San Jose State University

SJSU ScholarWorks

Master's Theses

Master's Theses and Graduate Research

1997

\title{
The relationship of the "Skills Plus" adult education program to its mission
}

Sharon Rebecca Altus

San Jose State University

Follow this and additional works at: https://scholarworks.sjsu.edu/etd_theses

\section{Recommended Citation}

Altus, Sharon Rebecca, "The relationship of the "Skills Plus" adult education program to its mission" (1997). Master's Theses. 1489.

DOI: https://doi.org/10.31979/etd.8zcv-xqmc

https://scholarworks.sjsu.edu/etd_theses/1489

This Thesis is brought to you for free and open access by the Master's Theses and Graduate Research at SJSU ScholarWorks. It has been accepted for inclusion in Master's Theses by an authorized administrator of SJSU ScholarWorks. For more information, please contact scholarworks@sjsu.edu. 


\section{INFORMATION TO USERS}

This manuscript has been reproduced from the microfilm master. UMI films the text directly from the original or copy submitted. Thus, some thesis and dissertation copies are in typewriter face, while others may be from any type of computer printer.

The quality of this reproduction is dependent upon the quality of the copy submitted. Broken or indistinct print, colored or poor quality illustrations and photographs, print bleedthrough, substandard margins, and improper alignment can adversely affect reproduction.

In the unlikely event that the author did not send UMI a complete manuscript and there are missing pages, these will be noted. Also, if unauthorized copyright material had to be removed, a note will indicate the deletion.

Oversize materials (e.g., maps, drawings, charts) are reproduced by sectioning the original, beginning at the upper left-hand comer and continuing from left to right in equal sections with small overlaps. Each original is also photographed in one exposure and is included in reduced form at the back of the book.

Photographs included in the original manuscript have been reproduced xerographically in this copy. Higher quality $6 " \times 9$ " black and white photographic prints are available for any photographs or illustrations appearing in this copy for an additional charge. Contact UMI directly to order.

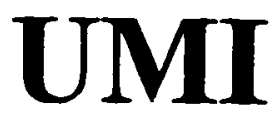

A Bell \& Howell Information Company 300 North Zeeb Road, Ann Arbor MI 48106-1346 USA 

THE RELATIONSHIP OF THE "SKILLS PLUS" ADULT EDUCATION

PROGRAM TO ITS MISSION

\author{
A Thesis \\ Presented to \\ The Faculty of the Department of Occupational Therapy \\ San Jose State University \\ in Partial Fulfillment \\ of the Requirements for the Degree \\ Master of Science
}

by

Sharon Rebecca Altus, OTR

August, 1997 
UMI Number: 1386190

Copyright 1997 by

Altus, Sharon Rebecca

All rights reserved.

UMI Microform 1386190

Copyright 1997, by UMI Company. All rights reserved.

This microform edition is protected against unauthorized copying under Title 17, United States Code.

\section{UMI}

300 North Zeeb Road

Ann Arbor, MI 48103 
Copyright $\odot 1997$

Sharon Rebecca Altus

ALL RIGHTS RESERVED 
APPROVED FOR THE DEPARTMENT OF OCCUPATIONAL THERAPY

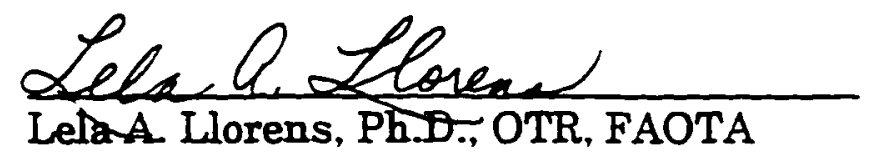

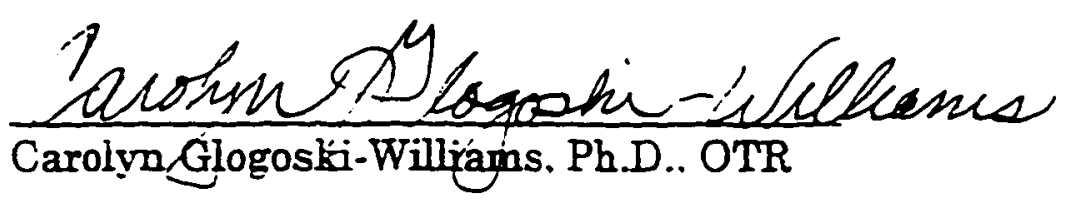

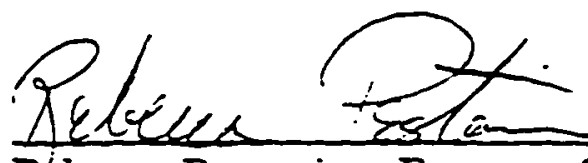

Rébecca Pestarino, Program Specialist Skills Plus

APPROVED FOR THE UNIVERSITY

In Sow Acurandenuth 


\section{ABSTRACT \\ THE RELATIONSHIP OF THE "SKILLS PLUS" ADULT EDUCATION PROGRAM TO ITS MISSION \\ by Sharon R. Altus}

The disruption in life course and occupational roles caused by the residual impairments following a stroke are not fully addressed under traditional, medically oriented practice. For needed long-term rehabilitation and education for individuals recovering from stroke, occupational therapists are developing roles in community-based programs.

Skills Plus is an Adult Education Program that provides rehabilitation and training for people who live with impairments resultant from stroke. In a classroom context, occupational therapists create a supportive environment in which individuals can continue therapeutic activities begun during medical treatment.

In-depth interviews were conducted with eight participants of the Skills Plus Program. Findings of increased independence and self-worth were reported. Participants generally considered the Skills Plus Mission Statement to be an accurate description of the benefits they perceived from participation in the Program. 


\section{ACKNOWLEDGEMENTS}

Thank you to the students and staff of the Skills Plus Program for their cooperation and encouragement to complete this project. Special thank you to all the students who agreed to participate in this study.

Thank you to my thesis advisor, Dr. Lela Llorens, for her unwavering assurance that I could do it, even when I was not so sure.

Thank you to Dr. Carolyn Glogoski-Williams for her valuable insight and suggestions.

Thank you to my program specialist, Becky Pestarino, for squeezing time to help with this project into her very busy schedule.

Thank you to Dr. Karen Diasio-Serrett, who was the person who first suggested I visit the Stroke Center in Santa Cruz, which led to my interest in the type of program studied here.

Thank you to Caroline Bliss-Isberg for her very valuable information and inspiration to become involved in the type of program described in this paper.

Thank you to every person who ever asked me the question, "How's your thesis going?"

Thank you to my family for keeping faith in me. It was a long haul. 


\section{TABLE OF CONTENTS}

ABSTRACT iv

ACKNOWLEDGMENTS $\quad$ v

1. INTRODUCTION 1

$\begin{array}{ll}\text { Purpose } & 1\end{array}$

$\begin{array}{ll}\text { Statement of the Problem } & 1\end{array}$

Research Questions $\quad 5$

$\begin{array}{ll}\text { Definitions } & 6\end{array}$

$\begin{array}{ll}\text { Assumptions } & 8\end{array}$

$\begin{array}{ll}\text { Limitations } & 8\end{array}$

$\begin{array}{ll}\text { Significance of the Study } & 9\end{array}$

2. REVIEW OF THE LITERATURE 10

$\begin{array}{ll}\text { Introduction } & 10\end{array}$

The Role of Occupational Therapy with Severe Disability 11

The Occupational Performance Model of Practice 12

Health Care and Successful Aging 13

$\begin{array}{lr}\text { Disruption of Occupational Roles } & 16\end{array}$ 
Social Support for Quality of Life After Stroke

Group Treatment for Chronic Illness and Promotion of

Wellness

Cost Effectiveness of Group Approach to Independent Living

Skills Training $\quad 22$

Adult Education Classes for Survivors of Stroke 22

$\begin{array}{ll}\text { Summary } & 23\end{array}$

3. RESEARCH METHODS 25

Research Design and Questions $\quad 25$

$\begin{array}{ll}\text { Informant Selection } & 26\end{array}$

$\begin{array}{ll}\text { Procedures } & 27\end{array}$

4. DATA AND RESULTS 29

$\begin{array}{ll}\text { Presentation of Data } & 29\end{array}$

Demographics $\quad 29$

$\begin{array}{ll}\text { Case Data } & 30\end{array}$

$\begin{array}{ll}\text { Mr. A } & 30\end{array}$

$\begin{array}{ll}\text { Ms. N } & 33\end{array}$

Ms. C 35

vii 
$\begin{array}{ll}\text { Mr. R } & 42\end{array}$

$\begin{array}{ll}\text { Ms. } P & 44\end{array}$

$\begin{array}{ll}\text { Ms. M } & 47\end{array}$

$\begin{array}{lr}\text { Ms. E } & 50\end{array}$

$\begin{array}{ll}\text { Results } & 53\end{array}$

Benefits and Drawbacks

Benefits $\quad 54$

$\begin{array}{ll}\text { Drawbacks } & \mathbf{5 7}\end{array}$

Quality of Life $\quad 60$

Skills Plus Mission Statement $\quad 64$

5. DISCUSSION, IMPLICATIONS, RECOMMENDATIONS

$\begin{array}{ll}\text { AND SUMMARY } & 67\end{array}$

$\begin{array}{ll}\text { Discussion } & 67\end{array}$

Implications for Occupational Therapy 68

$\begin{array}{ll}\text { Recommendations for Further Research } & 70\end{array}$

$\begin{array}{ll}\text { Summary } & 71\end{array}$

$\begin{array}{ll}\text { REFERENCES } & 73\end{array}$

viii 
$\begin{array}{lll}\text { APPENDIX A Skills Plus Mission Statement } & 78\end{array}$

$\begin{array}{ll}\text { APPENDIX B Permission Letter } & \mathbf{8 0}\end{array}$

APPENDIX C Participant Consent Form $\quad 82$

$\begin{array}{ll}\text { APPENDIX D Interview Guidelines } & 86\end{array}$

APPENDIX E Guidelines Added During the Interview Process $\quad 88$

$\begin{array}{lll}\text { APPENDIX F Interview Data Form } & 90\end{array}$ 


\section{CHAPTER 1}

\section{INTRODUCTION}

\section{Purpose}

The purpose of this study was to assess whether the Skills Plus Adult Education Program Mission Statement accurately describes the benefits perceived by the students in the program.

\section{Statement of the Problem}

Although medical technology is better able to keep more people alive despite severe physical disabilities, a large percentage of patients discharged from hospitals into the community are unprepared to meet the demands of daily living and are not motivated to reach and maintain projected functional levels of performance (Neistadt \& Marques, 1984; Versluys, 1980). Lack of confidence on the part of people who have physical disablities can adversely affect their functional performance and their ability to meet the demands of community living (Crewe, 1979; Neistadt \& Marques, 1984). However, as costs of medical care have continued to rise, time allowed for medical and therapeutic rehabilitation treatment has decreased (Yerxa, Clark, Jackson, Pierce, \& Zemke, 1990). 
As the population of adults with acquired physical disabilities increases, empowerment of this population becomes increasingly essential to the vitality of the entire community (Cole, 1979; Pendleton, 1990). With increasing medical costs and tightening health insurance practices, extended rehabilitation under the medical model has become unavailable to many adults who have recently acquired disabilities. Other avenues must be explored to realize a cost-effective, long-term approach to meet people's rehabilitation needs and to enhance their sense of competence in their activities. As satisfaction with ability to cope with the demands of everyday life increases, people are better able to fulfill their roles, and to be contributing members both of the family and of their communities (Crewe, 1979; Versluys, 1980).

The Skills Plus Program was created as a response to the need to provide continued rehabilitation for people with disabilities. The Program was originally modeled on the Cabrillo College Stroke Center in Santa Cruz, California. The Stroke Center was started by the Stroke Club, a support group of citizens who had had strokes and who decided they would like to have additional therapy. They procured the services of an occupational therapist. To obtain speech and physical therapy services, the Stroke Club members recognized the need for a funding base, at which time they contacted Cabrillo College. At that time, the community colleges in California had the mission to serve the special interests of the local 
community, and Cabrillo College provided the funding to professionally staff the Stroke Center. Funding is also provided by the cities in the area served, by the county, as well as by private fund-raising (Caroline Bliss-Isberg, Executive Director, Cabrillo College Stroke Center, personal communication, March 18, 1991).

Therapists in the Santa Clara Valley recognized the need for a program like that provided by the Stroke Center, and referred their patients. According to Rebecca Pestarino, Program Specialist for the Skills Plus Program, "When insurance expires and no longer pays for it, they [stroke survivors] are done as far as the medical community is concerned. But as you and I know, there continues to be a need for people to work on the skills that they learned. If you think of the trauma that has happened and the amount of information that has been given to them, it is difficult for them to absorb it all in..." (Rebecca Pestarino, Personal Communication, February 21 , 1996). However, the long drive from the Santa Clara Valley over the mountains to the Stroke Center was an ordeal for those who participated, and they often returned fatigued. It was like taking one step forward and two steps back, and they just did not have the will to go. So therapists started a program in Santa Clara, California that is similar to that provided by the Cabrillo Stroke Center. The founders of the Skills Plus Program decided to associate themselves with Santa Clara Adult Education, which 
began only a year or two before (Rebecca Pestarino, Personal Communication, February 21,1996).

The Skills Plus Program began and now offers an opportunity for persons with disabilities to continue therapeutic activities first learned during rehabilitation. Classes are offered in Independent Living Skills, Mobility, and Communication Skills. A group is also offered for caregiver training. Teachers at the Program are all certified medical professionals in their respective fields of occupational therapy, physical therapy, and speech therapy. After people who have suffered strokes have been stabilized and are finished with their traditional, formal rehabilitation through the medical community and insurance will no longer pay, they may be referred to the Skills Plus Program.

The Skills Plus Program, like the Cabrillo College Stroke Center, utilizes an education model. That is, participants register as students, and activities are presented in group format in a classroom setting. Teachers at the Skills Plus Program must hold Adult Education teaching credentials issued by the State of California, and classes must comply with both state and local education regulations and standards.

The Skills Plus Mission Statement (Appendix A) reflects the Program's commitment to enriching the community by providing "education and training for survivors of stroke and other neurological impairments" (Skills Plus brochure). 
Efforts to determine the students' reactions to the Program have been limited to survey questionnaires completed by students and caregivers. The results of these surveys included answers to a broad range of questions regarding student satisfaction; they did not allow for in-depth responses. Although there are also yearly meetings with the individual students and their caregivers, to date no in-depth evaluation had been conducted to determine the program's effectiveness.

\section{Research Questions}

This study explored the following questions:

1. What are the benefits and drawbacks perceived by the students in the Skills Plus Program?

2. In what ways, if any, does participation in the Skills Plus Program contribute to improved quality of life for students and their caregivers?

3. In what ways does the Mission Statement created by the Skills Plus administration and staff accurately describe the benefits perceived by the students? 


\section{Definitions}

The following operational definitions were used for this research study.

Skills Plus Program: A program run by Santa Clara Adult Education. It is specifically designed for survivors of stroke and other neurological impairments who are age 18 and over.

Students: Men and women enrolled in the Skills Plus Program. In this study, students are synonymous with participants and informants.

Caregiver: "Is a label given to those who provide assistance to people with limitations in adaptive function" (Davidson, 1991). Caregivers for students at Skills Plus are usually family members or hired aides.

Informants: Students at the Skills Plus Program who were interviewed for this research study.

Quality of Life: The operational definition used for this study is as follows: A person's subjective perception of life satisfaction and functional ability.

Therapy: Refers in this study to occupational therapy, physical therapy, and speech therapy, performed by certified medical professionals. 
Mission Statement: A declaration of purpose of an organization. The current Skills Plus Mission Statement was written by the program specialists (co-directors) and staff of the Program in Fall, 1995, with input from caregivers, students, and the advisory committee for the Program, and is as follows:

\section{SKILLS PLUS MISSION STATEMENT}

Skills Plus is committed to enriching the lives of the people we serve by:

providing a safe, supportive learning environment that stimulates and challenges

offering opportunities for increased independence, enhanced self-worth, and improved socialization skills encouraging students to achieve their maximum potential in making positive contributions to each other and to the community. 


\section{Assumptions}

The following assumptions were made for this study:

1. Informants will be able to describe their perceptions of their experiences accurately and meaningfully.

2. Informants will approach the interview seriously and will be candid and honest about their experiences at the Skills Plus Program.

3. Informants will be comfortable with the interviewer so that responses are truly representative of their viewpoints.

\section{Limitations}

The following are limitations of this study:

1. This study involved people who remained in the program for 6 months or more. It did not explore reasons why people left before 6 months.

2. Informant availability could have yielded a non-representative sample.

3. The sample size is small and cannot be generalized to a large population.

4. The interpretation of the information could be subject to researcher bias regarding the similarities found in the data obtained through openended questions. 


\section{Significance of the Study}

As medical costs place extended rehabilitation out of reach of many people, the education model provides a cost-effective method for the provision of occupational therapy services to people with long-term care needs. Programs such as Skills Plus provide an opportunity to maintain and continue work on physical, cognitive, and social function that began during medical treatment. The Skills Plus Program offers therapy in a classroom environment within the scope of an educational model. This research was designed to explore students' reactions to the Skills Plus program as a way to determine if the program achieves the aims of its mission. Successful outcomes at Skills Plus and similar programs could serve as a model for development and funding of additional programs. 


\section{CHAPTER 2 \\ REVIEW OF THE LITERATURE}

\section{Introduction}

The literature was reviewed regarding concepts of social and community support for survivors of stroke, their quality of life, and the role of occupational therapy in long-term programs for stroke survivors. The outcomes and cost-effectiveness of group programs for people with chronic illnesses including stroke was explored. The focus of this literature review is on elders living in the community.

In the last forty years, advances in medical technology and treatment have significantly extended the life expectancy of severely disabled people. This increasing life span has resulted in an ever-increasing population of people with long-term disabilities (Green, Pratt, Grigsby, 1984). However, "it was not until the 1960's that the issue of quality of life for the severely disabled was raised by society" (Neistadt \& Marques, 1984, p. 671). According to Crewe (1979), when the Amendments to the Rehabilitation Act was passed in 1978, a formal commitment to the goal of independent living for people with severe disabilities was made. 


\section{The Role of Occupational Therapy with Severe Disability}

According to Reilly (1969), the direct responsibility of occupational therapy is for patient achievement in her or his particular occupational role(s) in life. "The task of occupational therapy is to prevent and reduce the incapacities resulting from illness.... 'Reduction of incapacity' [is] the goal basic to all occupational therapy efforts" (p. 300). and is the "vital right" of every patient.

An American Occupational Therapy Association's roles and functions paper stated that, "as a profession, occupational therapy is committed to promoting environments in which the individual's worth can be recognized and the quality of life is valued" (American Occupational Therapy Association, 1989a, p. VI.35). The paper emphasized that while intervention often must begin in the hospital or rehabilitation center, the focus of such intervention "must culminate in the individual's own home and community environment in order to fully meet the client's needs" (p. VI.36). It restated the commitment of the profession to "a service which supports the goals and process of independent living" (p. VI.35). This commitment applies to individuals at every stage and condition of life. According to Pedretti (1996), "the performance of tasks and roles essential to productive living throughout the lifetime is also central to the definition of occupational therapy" (p. 6). 
The Occupational Performance Model of Practice

The Occupational Performance frame of reference described by Pedretti \& Pasquinelli (1990) was originally used in conceptualizing the current study. In 1994, the occupational therapy domain of concern was refined and expanded, as described in the third edition of Uniform Terminology for Occupational Therapy. The parameters of occupational therapy's domain of concern were defined as including performance areas, performance components, and performance contexts (American Occupational Therapy Association, 1994).

Conforming to this intention to "capture the essence of occupational therapy succinctly for others" and to "reflect current practice" (American Occupational Therapy Association, 1994, p. 1047), occupational performance was re-elucidated as a model for practice, a system in whose context treatment can be carried out (Pedretti, 1996). Occupational performance frame of reference embraces both performance skills (later named areas) and performance components utilized for those skills, while including considerations of the individual's environment (Pedretti \& Pasquinelli, 1990). In the occupational performance model, "life space influences" are further elaborated as performance contexts consisting of temporal contexts and environmental contexts. 
According to Christiansen (1991), "the goal of occupational therapy is to prevent, remediate, or reduce dysfunction relating to occupational performance" (p. 33). The inclusive, holistic occupational performance model is appropriate for exploring individuals' life experiences, and the refined model remained the basic conceptual system used in this research.

\section{Health Care and Successful Aging}

The health care system in the United States has been medically oriented with an emphasis on curative care, and the realm of long-term care remains a poorly defined, barely insured end on the continuum (Safran, Graham, \& Osberg, 1994). Over the past decade, the direction in the care of elders has been shifting from the prevailing problem-based biomedical model, with its emphasis on problems, deficits, and functional abilities, to a more humanistic model of care, with an emphasis on quality of life as perceived by the individual and his or her family (Clark, 1995). In a discussion of aging in the United States, Perry stated, "...to guarantee 'successful aging' for as many of our citizens as possible, we need to transform this nation's thinking about growing old.... Chronic diseases that most frequently strike in later life are now the most common form of illness in the United States... Although seldom a cause of death, these problems are the cause of much dependent 
care and a greatly diminished quality of life for millions of Americans" (Perry, 1995, p. 154).

Reviews of the literature have shown that there is no consensus on a clear definition of the term "quality of life" (Clark, 1995; Farquhar, 1995). In a comprehensive review of empirical research on interpretations of the concept of quality of life as it is used in communication among health care providers (physicians and nursing), social workers, and consumers (patients and families), Clark (1995) demonstrated how quality of life had different meanings to different people, both providers and consumers of care. Clark identified a lack of input from elders in personally defining their needs, resulting in a gap between the professional and the layperson in defining quality of life for elders with disabilities. While physicians emphasized strictly health-related values, elders expressed values relating to self-identity and physical comfort. Clark stated that an overemphasis on concepts of individual functional independence was often found in the gerontological literature, and that this over-reliance on simple individual autonomy may ignore the critical contributions made to life by a sense of community and social support. Clark also looked to the independent living movement for discussion about autonomy not as whether or not individuals have disabilities, but rather as the power of individuals to make decisions, to control their use of services, and to act on their own goals (i.e., their perceived control). 
In a review of literature regarding quality of life, Farquhar (1995) found that "definitions of quality of life are as numerous and inconsistent as the methods of assessing it...as different people value different things...no indicator can ever be comprehensive enough for all uses" (p. 1440). In medical and nursing literature, definitions of quality of life were often limited to components of the whole concept, such as measures of physical functioning. In social gerontology, subjective indicators of life satisfaction and perceived life quality were often used. In health services research, the emphasis was on general health and functional ability. Farquhar found that because both objective and subjective indicators were used as measures of quality of life, it was difficult or impossible to directly compare results of different scales and tests.

"However, health is not the only dimension of quality of life" (Farquhar, 1995, p. 1440). In a study to identify individual's views of the quality of their lives and of the ability of elders to talk about the concept of quality of life, Farquhar drew upon samples of people aged 65 and older who lived at home in two areas of England that differed geographically, socially, and economically. In stage one of the study, 210 respondents were asked a brief set of unprompted open questions regarding the quality of their lives. The results of the study indicated that for older people living at home, quality of life included family relationships, social contacts, activities, emotional wellbeing (including life satisfaction), adequacy of material 
circumstances, and suitability of the environment, as well as general health and functional ability.

Clark (1995) reviewed current changes in geriatric medicine and nursing theories of practice for care of elders who suffer from chronic, disabling conditions. The problem-based bio-medical model is being replaced with holistic, goal-oriented models of health care which incorporate empowerment of the client in defining quality of life.

"In the goal-oriented framework, health is defined not as an outcome, but as a process, incorporating the following dimensions: physical maturation and differentiation, self-actualization, development of adaptability and coping skills, and the acquisition of wisdom--all potential aspects of quality of life considerations" (Clark, 1995, p. 408).

\section{Disruption of Occupational Roles}

A study by Becker (1993) illustrated the profound disruption that a stroke caused in individuals' lives, and the subsequent difficulty of making alterations in daily life to create a sense of continuity of life course. In a portion of a larger qualitative study, investigators employed three in-depth interviews with thirty-six stroke survivors who had returned home from the hospital, beginning at the time that home care services were withdrawn. The interviews with each respondent took place over the period of a year, from 4 
to 16 months after the stroke. The researcher found that "When a stroke occurs, the known self is thrown into disarray.... [For most stroke victims], 'real' life--as they knew it before the stroke--appears to have ended" (Becker, 1993, p. 151). The relationships between self, body, environment, and daily life have to be redrawn in the effort to restore the fabric of predictable, everyday life. In analyzing the data, the dominant theme that Becker uncovered was "how lengthy the process of life reorganization was: most often life reorganization was not complete as the study ended" (Becker, 1993, p. 154). Study respondents experienced difficulty in attempting to return to previous roles, resulting in greatly increased social isolation. The number of activities in which most people actively participated, both inside and outside the home, was greatly reduced. Becker concluded that a holistic approach was needed to increase and refine understanding about disruptions in life continuity later in life, to more adequately develop policies and services that facilitate older persons' ability to restore a sense of continuity to their lives.

\section{Social Support for Quality of Life After Stroke}

The majority of stroke patients have residual impairments that impede some aspect of their ability to care for themselves at the time they are discharged to the community (Safran, Graham, \& Osberg, 1994). "Socialization activities outside the home were affected most dramatically" 
(Kelly-Hayes \& Paige, 1995, p. S31). Social support and life satisfaction are among the factors that affect the patient's rehabilitation process and adjustment. The social context in which a stroke patient recovers has profound effects on the success of the recovery process (Kelly-Hayes \& Paige, 1995). In an examination of the quantity and quality of social support systems for two distinct groups of people with disabilities (adults who had survived either stroke or spinal cord injury), McColl and Friedland (1994) cited several studies that showed that social support was known to be related to positive adaptive outcomes.

Community relationships were also noted to be important for individuals recovering from strokes, and to warrant further development for their potential to promote positive adjustment outcomes. McColl and Friedland (1994) found, however, that most community support, such as that provided by the Independent Living Movement, has focused on people with disabilities of relatively early onset. They also found that those support groups that existed for people who have had strokes did not tend to have the same broad public mandate as other organizations. They stated that these findings sent up a "red flag" for the support needs of survivors of stroke.

Safran, Graham, and Osberg (1994) found that in the United States, medically oriented insurance practices contributed to the prevention of the emergence of more comprehensive coverage for community-based care, and 
that community based and noninstitutional care services had a difficult struggle for legitimacy.

\section{Group Treatment for Chronic Illness and Promotion of Wellness}

Studies by Kurasik (1967) and by Gauthier, Dalziel, and Gauthier (1987) have found that peer support and encouragement in group treatment promoted wellness. Kurasik (1967) reported on a 10-week project involving 15 patients with hemiplegia at a Veterans Administration Hospital to determine whether there were differences between the group method and the individual method of rehabilitation treatment. On the average, the patients who received group rehabilitation achieved their maximum goals eight days ahead of the individually treated patients, were somewhat better adjusted and accepting of their condition, and had started planning for the future. In contrast, the individually treated patients lacked acceptance of their condition and had no interest in future planning. Kurasik concluded that group rehabilitation was more effective "provided the therapist 'treats' the complex personality rather than specific conditions" (p. 853). Among the reasons given for the group patients' success were: 
1. In group rehabilitation, the patient sees him or herself as a member of the 'disability' unit.

2. The patient can see others sharing his or her pain, sorrow and necessary adjustment, and is not alone with his or her handicap.

3. The patient can envisage adjustment to his or her disability.

4. The patient is able to participate in all the activities performed by patients having the same physical capabilities.

5. As one of a group, the patient is better motivated to reach his or her objectives.

6. The patient benefits from the repetition of instructions and can see how things are done by others. (pp. 853-854).

Kurasik stated, "group therapy played a major part in the process of restoring handicapped patients to become useful members of society at the earliest possible moment" (p. 854).

Using a two-group experimental design, Gauthier et al. (1987) demonstrated that an outpatient rehabilitation program using an occupational therapy group approach was of benefit to a group of persons with Parkinson's disease in maintaining their functional status, when compared to a control group. They noted improved physical and motor symptoms and improved psychological well-being and quality of life. They concluded that "group therapy is well suited for patients with chronic degenerative diseases who are easily drawn into depression and social 
isolation. The group provides a supportive environment and facilitates interactions among peers" (Gauthier et al., 1987, p. 363). They recommended that in group occupational therapy sessions, "interventions addressing motor and functional problems should be coupled with interventions aimed at improving socialization, motivation, interpersonal and family relationships, self-esteem, and knowledge of the disease" (Gauthier et al., 1987, p. 364).

According to Versluys (1980), a high percentage of patients is discharged from the medical setting unprepared for the demands of daily life and unmotivated to reach and maintain their highest levels of performance. Group members can see that others with similar problems have struggled and succeeded, increasing motivation and encouraging a feeling of social acceptance Versluys (1980).

Trends toward increased occupational therapy practice in community settings as well as toward increased use of groups in these settings was noted by Duncombe and Howe (1995), who surveyed occupational therapists in current practice. Independent living skills programs can be provided in group or classroom format, which creates an atmosphere for peer support and contributes to class members' cognitive and emotional growth (Neistadt \& Marques, 1984). 


\section{Cost Effectiveness of Group Approach to Independent Living Skills Training}

Group treatment has been found to be cost effective (Duncombe \& Howe, 1995; Gauthier et al., 1987; Neistadt \& Marques, 1984). DeJong and Hughes (1982) approached independent living skills training from a longrange policy perspective. Overriding long-range outcomes that they proposed as relevant to public policy-makers and funding sources were: (1) whether a person can live in a less restrictive environment, and (2) whether a person can be a productive member of society. Less restrictive living arrangements require less public financing and are preferred by policy-makers to higher cost structured residential settings. The concept of productivity has been recognized to include not only gainful employment, but also contributions to community and family life such as in homemaking, child care, and participation in formal organizations. Thus the benefits of group treatment have been seen to be cost effective in both the short and the long run.

\section{Adult Education Classes for Survivors of Stroke}

The role of an occupational therapist in a community group setting was described by Duncombe and Howe (1995) as being similar to that of an educator, rather than to that of a traditional group leader. A search of the 
education literature revealed information that addresses adult education for people with developmental disabilities as well as literacy and high-school diploma classes. No information was found regarding public school-based programs specifically for adults suffering from disabilities secondary to acquired neurological difficulties such as stroke.

\section{Summary}

This literature review addressed: roles of occupational therapy in severe disability, the occupational performance model of practice, health and quality of life for elders, disruption of occupational roles by stroke, importance of social and community support after stroke, use of group treatment in chronic illness and stroke for promotion of wellness, cost effectiveness of group approach to independent living skills training, and adult education classes for survivors of stroke.

The domain of concern for the occupational therapy area of practice is the maximum achievement of a person's tasks and roles throughout the lifetime, and the promotion of environments in which each individual's worth is recognized. The literature reflects increasing societal interest in and commitment to independent living and quality of life for people with severe disabilities. While definitions of quality of life vary, the problem-based, 
biomedical model of health care for elders is being replaced by holistic, goaloriented frameworks.

The literature documents the profound disruption in both occupational roles and community relationships as the aftermath of stroke. Social support has been found to be an important factor in recovery and positive adjustment, yet there has been scant community support for people who have survived strokes.

Several studies have demonstrated that group treatment, with its inherent peer interaction and support, promotes wellness. It was also found to be highly cost effective for the general community. Group occupational therapy in an adult education context has not been addressed in the literature. 


\section{CHAPTER 3}

\section{RESEARCH METHODS}

This study was designed to examine whether The Skills Plus Adult Education Program Mission Statement accurately describes the benefits perceived by the students in the program.

\section{Research Design and Questions}

A multiple case-study design utilizing in-depth interviews was used to answer the following questions:

1. What are the benefits and drawbacks perceived by the students in the Skills Plus program?

2. In what ways, if any, does participation in the Skills Plus program contribute to improved quality of life for students and their caregivers?

3. In what ways does the Mission Statement created by the Skills Plus administration and staff accurately describe the benefits perceived by the students?

Data from in-depth interviews with eight students in the Skills Plus Program were used for this study. 


\section{Informant Selection}

Informants in the study were a purposive sample as described by DePoy and Gitlin (1994). Students who met the following criteria were identified by this researcher and the program specialist. Each informant in the study was required to have:

1. Participated in Skills Plus for at least six consecutive months during the two years prior to the first interview date;

2. Taken part in at least one Independent Living Skills class per program day attended as a part of the individual's regular program schedule for at least six months;

3. Adequate auditory comprehension skills to understand the questions.

4. Sufficient verbal language ability to answer adequately and reliably.

In selecting from the list of eligible students, an effort was made by the program specialist. to achieve demographic diversity in the group selected. Both men and women were chosen, and they varied in class sessions attended, living situations (alone, with spouse, with other family, with employed caregivers, in group homes), level of assistance required from another person for mobility and/or for basic self-care, length of time attending the Program (several years, or one year or less), and age. Although 
the researcher originally intended to interview five or six people, eight informants were selected. Oral requests to participate in the study were presented individually to each potential informant by the researcher. These requests were made at the Skills Plus Program during breaks between classes, with assurances that participation was completely voluntary. When one person declined to participate, a request was made to another selected student who met the criteria.

\section{Procedures}

Permission to interview students for the purposes of this study was obtained from the Director of Educational Options, Santa Clara Unified School District (Appendix B).

Each informant was asked to sign a consent form (Appendix C) that included the following: 1 . permission to audiotape record interviews by the researcher with the participant regarding the participant's personal experience of the Skills Plus Program; 2. a description of participants' rights, and 3. assurance of confidentiality.

An individual in-depth interview was held with each informant. Each informant chose to have the interview conducted at his or her home. Interviews took place during July and August, 1996. Six interviews were conducted privately; one took place in the presence of an employed caregiver, 
and one took place within the hearing of a spouse. The interviews lasted between 40 and 80 minutes, averaging 58 minutes. The researcher made an effort to maintain a relaxed atmosphere.

During the initial portion of the interview with each informant, the researcher followed interview guidelines consisting of open-ended questions prepared by the researcher (Appendix D). Demographic information was also requested at this time.

Near the end of the first interview, the researcher showed the research questions to the informant to stimulate further comments. This procedure was successful in eliciting elaboration of the informant's experiences, and was then used in all the interviews. Finally, each informant was asked to comment on each part of the Skills Plus Mission Statement for accuracy, exaggerations, or omissions. As interviewing proceeded, additional questions arose as a result of participants' statements, questions, or concerns, and these were added to the interview guidelines (Appendix E).

The recorded interviews were transcribed by the researcher. The tapes and the transcriptions were reviewed to compile the data. The data from each interview was organized according to the Interview Data Form (Appendix F). The data were analyzed to determine themes common to all informants and to answer the research questions. 


\section{CHAPTER 4}

\section{DATA AND RESULTS}

\section{Presentation of Data}

A summary of the demographics of the informant group interviewed for this study is presented, followed by individual case data.

\section{Demographics}

The 8 participants interviewed for this study included 5 women and 3 men, who ranged in age from 61 to 82 years, averaging 73 years of age at the time of the interviews. The amount of time between their strokes and the dates of their interviews ranged from 1 year 6 months to 8 years 6 months, with a mean of 3 years 4 months. The length of time in attendance at the Skills Plus Program was between 10 months and 4 years 6 months, with a mean of 2 years 1 month. Five of the participants interviewed lived with a spouse, 1 lived with a son, 1 lived with a spouse and also had a part-time employed caregiver during the day, and 1 lived alone and had part-time employed caregivers during the morning and evening hours. Three of the participants were independent in basic self-care, the other 5 needed various levels of assistance. Two of the 8 persons interviewed participated in cooking 
and other light household tasks at home. Five of the participants were independently mobile in and around their own homes, 4 were mobile around their immediate neighborhoods, and I could also drive longer distances independently.

\section{Case Data}

Case data are presented as summaries of the information obtained during the interview process which was taken from the interview data form. Information and demographics in each summary describe the situation that was current at the time of the interview.

Mr. A

$\mathrm{Mr} . \mathrm{A}$ is a 76-year-old man who, at the time of the interview, was living in a private home with his wife, who was also his main caregiver. Mr A. was "pretty self-sufficient" in basic daily living activities, able to feed, toilet, bathe and dress himself. Larger household tasks had been assumed by his wife. He was independently mobile. He walked with a cane around the house, used an electric scooter for longer distances, and drove an adapted van that he could load his scooter into independently.

Mr. A suffered a stroke in December, 1987, 8 years and 7 months prior to the interview. After rehabilitation and home care, he attended the Skills Plus Program for 2 years, then for several years participated 4 to 5 times a 
week in other adapted physical education and swimming programs that had more equipment available. When those became too strenuous, he returned to the Skills Plus Program, and had been in the Program for 2 years at the time of the interview.

Mr. A reported that he enjoyed going to the Skills Plus Program and that his experiences there had all been positive. Although he did not spend a lot of time socializing there, he believed that the interaction with other people was beneficial. He believed the Program "meets my needs in as much as we set goals, and try to work toward those." Particular areas in which he noted an improvement were mobility and facial control. Although he had not seen any recent improvement in his condition, he stated that the training he received when he first attended the Skills Plus Program had helped him "out there," and made him feel more self-sufficient. He valued the fact that the instructors at the Skills Plus Program were all trained therapists.

About his family, Mr. A commented, "My wife is all for it [his participation in the Skills Plus Program]. Probably gets me out of the house, out of her hair." She had many social activities independently. She also benefitted from the monthly caregiver meetings offered by the Skills Plus Program.

Socially, Mr. A sometimes saw other people outside the home, such as his neighbors, friends at local church events and at a Senior Men's group 
special holiday luncheons when wives were invited (his wife insisted they attend), and table companions on occasional vacation cruises.

He believed that students at the Skills Plus Program made positive contributions to each other, "because they [the other students] are always encouraging you, saying what a good job you are doing, you're looking good." Mr. A did not know whether other students were active in their neighborhoods. In terms of benefits to the general community, Mr. A stated, "Well, number one, it makes it imperative that you participate in the exercises, which I know in my case I know I wouldn't be doing on my own. So in that respect it's something I feel is beneficial for everyone."

Mr. A perceived that the program benefitted students in two main ways. First, "It gets us off our rear end[s], and enables us to participate in the exercise. And I've always liked exercising, I don't figure it as a chore. In fact I used to be a jogger, and I used to jog on my own. [I would not exercise] as much as I do by going there...." Second, "I think it's always beneficial to mix with people."

Mr. A could not think of any drawbacks to the Program. Ms. $\mathbf{N}$

Ms. $\mathrm{N}$ is a 72-year-old woman who, at the time of the interview, was living in her own home with her youngest son, who was 29 . She received a lot of support from her children and friends. She independently performed her basic activities of daily living, did most of her own cooking, and "I 
sometimes sweep the floor, sitting down, with a push broom." The major housekeeping and the yard work were done by her son and a daughter-inlaw. She ambulated independently using a walker, and she also had an electric scooter, which she used for getting around her local neighborhood. She depended upon other people to drive her longer distances.

Ms. $\mathrm{N}$ suffered a stroke 3 years and 3 months prior to the interview. She had several months of therapy, both in the hospital and at home. She had been attending the Skills Plus Program for $21 / 2$ years at the time of the interview.

Ms. N enjoyed the friendly environment of the Skills Plus Program. She said that being in a group motivated her to do better. She derived inspiration from the performance of other students. She described several cooking techniques and adaptive items that she learned about in the Program that she now uses at home. She stated that the Program met her needs in her daily life. "walking and just about everything." She demonstrated the improvement in her use of her affected hand. She noted that when home responsibilities had kept her from attending the Program for a month, she had perceived a decline both in her walking abilities and in the strength of both hands.

An element that Ms. N reported as important about the Skills Plus Program was "the company of other people. Because it's different when you exercise at home alone, and when you have other people. And the teachers 
are nice...You don't do, like you say, 'I'll do that tomorrow.' But at Skills, you really do it. Whether you like it or not."

Ms. $\mathrm{N}$ discerned several ways in which her participation in the Program had reduced the stress on her family and neighbors. As she became more independent and self-reliant, she called on them less frequently for help. "Although, at first, before I went to Skills, I used to go on my scooter... I used to call them all the time...You find ways, and you learn, 'What did I learn from the school?"' She said that her family believed that she was getting the help to be able to do "normal things." Whereas her daughter had been worried before, and had visited daily, she "feels free now to go away on vacation, and she knows that I know what to do now, and who to call."

Ms. $\mathrm{N}$ reported that the positive contributions the students made to each other came from the feeling of family, "like they're your own brothers or sisters...We try to help one another. Like when someone won't do it they said, 'Come on, come on, do it.' And we try to encourage each other." She did not feel she had any contribution to make to the general community "because I can't do anything."

Ms. $\mathrm{N}$ stated that it was important to have the classes taught by certified therapists in order to be sure she got the right instructions. She described a friend who showed her things to do that were contrary to the therapy she had received. 
During one 8-week session of the Skills Plus Program, Ms. N had tried to attend for $\mathbf{4}$ days per week. She found it was too much for her, partly because she needed time for all her tasks around the house.

The only drawback Ms. N saw was that "if you don't have transportation, you can't go."

Ms. C

Ms. C is a 61-year-old woman who, at the time of the interview, was living in her own home with her husband. She had a hired caregiver who stayed with her during the day while her husband was at work. Her children lived outside the local area, but visited occasionally and were supportive when needed. Ms. C fed herself, but needed assistance for other basic activities of daily living (bathing, dressing, toileting). Ms. C and her caregiver prepared lunch and dinner together. Ms. C stayed home a lot and did not usually see a great variety of people besides those at the Skills Plus Program. She occasionally served as a volunteer stroke patient at a hospital health-care education program.

Ms. C had a stroke 1 1/2 years prior to the interview. She had in inpatient, outpatient, and home health therapy, and had been attending the Skills Plus Program for 10 months at the time of the interview.

Ms. C's impression of the Skills Plus Program was that, "It's not therapy, it's movement." When asked about her experiences at the Skills Plus Program, she expressed a wish that it would be more challenging, and 
said, "I think you continue what you already know how to do, and you stay limber, and that's very important, too." She believed she would not do as much exercise and activity if she were not attending the Program. She found working in a group "interesting," and appreciated being exposed to the variety of different problems that different people had. She often described her experiences in terms of other people in the Program, and her impressions of those people. For example, when asked about her experience at Skills Plus, she responded, "I don't know that anyone has learned how to walk since they've been there." She stated that she perceived other people's problems as worse than her own, a perception that made her feel better.

Ms. C emphasized the importance of self-concept and communications, and felt that these areas were handled well in the Skills Plus Program. She described the environment as set by the staff, as positive, and added, "You don't end up feeling like you are less of a person when you leave."

Ms. C did not believe that skills learned at the Skills Plus Program were useful in her daily life, although she did say that she used equipment in the cooking class that she wanted to use at home. Meanwhile, she reported that the social contact and communication aspects of the Program were important to meet her needs, in that the interaction with other students provided critical thinking and intellectual challenge. (Ms. C did not require or participate in any Communication Skills classes.) 
The most important aspect of the Program for Ms. C was the people, and the opportunity to "laugh a little about yourself." She appreciated both the effect of a regular schedule for her life, and the variety of activity offered to her daily routine. She commented, "I think there's a vacant spot in your week if you don't go...you've missed the people, and the activities, and the routines. All of which I think are really helpful."

Ms. C said that she had been told by one of her former therapists that she seemed much more self-confident than she had been in the hospital. She seemed to attribute this improvement in part to the problems she had with transportation to and from the Program, which was an issue for her. "You get out, and you travel, you have to handle the damn bus...something always seems to go wrong there...it's the survival again....I think the more you get through, the better you feel about yourself, and the stronger you are."

In discussing the effect of the Program on her caregiver, Ms. C again compared her situation with that of other people. She believed that by being exposed to other students' problems, her caregivers had the opportunity to see more than just what is wrong with her, thereby making her situation appear more acceptable to the caregivers.

As for contributions students made to each other, Ms. C indicated, "Just the exposure....We all see each other at our worst, at our most vulnerable state....It's helped us put our own life in perspective a little bit better." As for contributions by the students to the general community, she 
believed that was a "larger picture I don't quite have. Except that it helps each of us, and we, each in turn maybe become closer to the time when we are going to be making more positive contributions to the community ourselves." She believed that the students at the Skills Plus Program were the type of people who had made contributions to their communities prior to their strokes, and that the Program was supporting them to return to community activity.

Ms. C reported that one of the biggest benefits of the program was the opportunity to work and interact with other people to accomplish a particular task. There was "remarkably" almost always something for everybody to do, despite the wide range of ability levels.

As a drawback to the Program, Ms. C questioned whether people at either of the extremes of ability level might fail to be included in some way. She observed that group experience generally serves the average ability level of the group. "I don't think the extremes are covered. necessarily. Like the one that can't communicate at all...." However, she herself had not experienced any limitations.

Ms. C felt that the Skills Plus Program was valuable "because it deals with someone's self-worth." She believed that it offered opportunity for positive feedback, which she valued as very important when people were so vulnerable. She stated that when self-worth is enhanced, "everything else 
follows," and when self-worth is not enhanced, then "the other stuff won't be able to follow, whatever it might be."

Mr. J

$\mathrm{Mr} . \mathrm{J}$ is a 71-year-old man who, at the time of the interview, lived alone in a mobile home park. He had hired caregivers who came in the morning and again in the evening; he was alone for a few hours during the day and for the entire night. His children and grandchildren lived 50 miles away, and he said that he did not understand why he saw them only rarely. He apparently received little, if any, family support. He fed himself, but required assistance for most other basic activities of daily living (bathing, dressing, toileting).

Mr. J complained of depression, and said he felt trapped like a prisoner when alone at home, and "things start working" (i.e., depressive thoughts). He was determined not to give up his "little abode" and live in a long-term care facility. His mobility was limited--he required close supervision to transfer safely. He had an electric scooter that he used to go outdoors and to drive around the mobile home park, but depended upon transportation services for farther distances.

Mr. J suffered a stroke about 1 1/2 years prior to the interview. $\mathrm{He}$ was unclear about the amount of rehabilitation he had received after the stroke. He had been attending the Skills Plus Program for 1 year. 
Mr. $J$ found the Skills Plus Program to be different from what he had expected. He stated that he learned more from the association with students whom he considered worse off than himself than he did from his own experiences or from the therapists. The other students made up the nature of the environment of the Program for Mr. J, and he said he could swing from being depressed to feeling happy with everyone.

Mr. J said that exercises performed at the Skills Plus Program had helped relieve tension in his legs and had made transferring to his bath bench at home easier. He also learned not to be as negative as he had been, and could notice the effect of his negative remarks on other people. The Program met his needs by offering something to look forward to, "an outing." Although he did not see that he had made any progress, he did think that participation in the Program had made him feel more self-sufficient. However, he lost much self-confidence after falling at home when he was alone.

Mr. J did not perceive any effect from his coming to the Skills Plus Program on his family. He thought that if he were married it would have had some effect. He was ambivalent about whether there was any benefit to the hired caregiver who accompanied him to the Program.

Mr. J described several changes in his relationships with others that resulted from his participation in the Skills Plus Program. "I've made new friends. When I got sick I started seeing things I didn't know existed....Some 
people are so bad off....At first I didn't have any patience with [other students]. Then [my tolerance] stretched and stretched. You know, they are human. I can relate more now than I ever could....I developed the skill of thinking about others since I've been to school [i.e. Skills Plus]."

Mr. J believed that students at the Program made positive contributions to each other through the fact that people had complimented him on his improvement. However, he did not believe they could make contributions to the general community yet because they were "not able to do anything."

Having the classes taught by certified therapists was very important to Mr. J. He did not want to be told to do anything that might hurt himself or someone else, asserting, "I want somebody that's familiar with the broken bones department." Benefits directly perceived by Mr. J were social and communication skills. "I think it sharpens you a little bit. Otherwise, I would be talking to my pillow:" (He does not take any communications classes at the Program.) He declared, "I could always talk to people. But to approach someone that I'm not even sure they can understand me, was very difficult. So it's easier to avoid them. But now I can go to [them]."

Drawbacks he mentioned were that classes were repetitive. While admitting that he had not expected "television," he found the routines of the program "very boring...Unless we're making jokes." Apart from social skills, he did not think he had learned any skills that he could use. He also wanted 
more individual activity, and believed that if classes were smaller, they would be more beneficial. He said he had no way of gauging his mental or physical abilities. He needed to be encouraged to perform his exercises. Mr. R

Mr. $R$ is a 70-year-old man who, at the time of the interview, lived in an apartment with his wife, who was also his main caregiver. His daughter and grandchildren lived in the same apartment complex. His family was very close and supportive. Mr. $R$ feed and toileted himself; his wife assisted him with bathing and dressing. When asked whether he helped, he replied "I try to. Sometimes I get in the way." His wife also took care of the housework, cooking, and shopping. Mr. $R$ used a cane to get around the apartment, and also for short walks around the complex, which he made part of his routine. He also walked short distances (20 feet or so) around the apartment without the cane. He used a wheelchair for longer trips so he would have a place to sit down. He was considering trying to drive again.

Mr. $R$ had a stroke $21 / 2$ years prior to the interview. He received therapy for 6 months, until he was discharged from the hospital. He joined the Skills Plus Program 1 month later, and at the time of our interview, had been a student there for 1 year and 9 months.

Mr. $R$ described the Skills Plus Program as a "new experience." Spending time in a group with other people was meaningful for him, rather than "sitting at home by yourself." It surprised him that people "in worse 
shape than me" were encouraging him and trying to help him out. He said that ever since he had improved, he tried to help newcomers.

Mr. $R$ reported that it was easy to learn at the Skills Plus Program. He found the environment stimulating, and his only complaint was that some of the students did not want to respond. "Some of the teachers had to put up with a lot of stuff." He said that the Program offered some challenge, but stated that it lacked a "hard core challenge." He recommended, "Just keep moving, don't let them sit still."

Mr. $R$ was aware of his limitations, and wanted to do as many things as possible by himself, without being a burden on somebody else. At the Skills Plus Program, he learned to walk better, to move his affected arm more and to do more things one-handed. Improvements in his ability to do a bit more for himself boosted his sense of independence and self-sufficiency. He said that the Program met his needs by giving him the exercises to carry out, which he normally would not do at home, and by offering him an opportunity to get out, meet people, and keep busy.

Mr. $\mathrm{R}$ did not believe his participation in the Skills Plus Program had any significant effect on his family. "They would rather have me go out than sit around like a bump on a log." At the same time, when students enjoy themselves and feel better, there is "less of a hassle on the caregiver." His family was acquainted with many of the other students, and going to the Program also gave him something to talk about at home. 
Mr. $R$ viewed the contributions students in the Program made to each other in terms of his own encouragement of other students, and his desire to see everybody there improve. He thought they helped each other as well. He felt that laughter was important, and did his part to offer humor. He did not expect students to be active members of the general community, "because they're handicapped and can't do enough to really get out there and participate in what everybody else is doing. They just have to sit back and listen and watch."

Mr. $R$ believed the Skills Plus Program benefitted students by getting them started, by offering them physical and mental stimulation, and by helping them to help themselves. He appreciated working together with other people as a group or team, and the opportunity to enjoy life.

The major drawback that Mr. R perceived was the inconvenience of transportation to the Program. He also believed that there was not enough exercise equipment.

Ms. $\mathbf{P}$

Ms. $P$ is a 74-year-old woman who, at the time of the interview, was living in a private home with her husband and one adult son. She could feed and toilet herself independently. Her husband helped her to bathe and dress. Cooking and housekeeping tasks were performed by her husband and son. However, Ms. P declared that the family was planning to move to a smaller place, at which time she intended to again do the family cooking. 
She could ambulate independently without a cane. However, she was dependent upon her husband for driving any distance. She said she had loved driving before she had her stroke, and stated her desire to drive again.

Ms. P suffered a stroke 1 year and 9 months prior to the interview. She received both inpatient therapy and home health rehabilitation for about 2 months. She had been attending the Skills Plus Program for 1 1/2 years at the time of the interview. She had considered going to an adaptive physical education program, but thought it was more than she could handle.

In describing her experiences at the Skills Plus Program, Ms. P remarked that going there lifted her out of her "foul mood." She said she enjoyed the companionship, the laughing, and the activities. She described the environment of the Program in terms of the encouragement she felt from her interactions with other students in two very different ways. First, she said, "you got something to laugh about." Second, "... you look at somebody else, and what has happened to them. And it encourages you because you think, 'Gee, well, I'm doing better than that one.' Anyway, that's kind of a selfish attitude, but you can't help but feel that way."

Ms. P believed that she had learned many skills in the Skills Plus Program that were of benefit to her in her daily life. She asserted that she had improved in strength, in the use of her affected hand, and in walking. As a result of these improvements, she was able to travel from her house to her yard by herself, which helped her with exercise. She described how she 
would find ways to use her affected hand in performing her daily activities, although she often felt "aggravated with this hand." She claimed that participation in the Program had improved her attitude. "I don't feel so like I'm a prisoner, or whatever, of my own self." She was concerned about the upcoming 3-week summer break from classes, unsure whether she could "force" herself to do the exercises, and afraid that she might become less strong.

The Skills Plus Program met Ms. P's needs in several areas. She said that she saw the importance of exercise, and that her husband had been "trying to help." But alone she got discouraged, so she decided to join the Skills Plus Program, because it offered activities and exercise in a group setting. Second, she was able to obtain useful information from other students. Third, she found being at the Skills Plus Program an uplifting experience, and she was thankful to "just feel better."

In terms of her family, Ms. P depicted the Skills Plus Program as an outlet for her husband. She said that he "moaned" about rushing around in the morning to drive her there, but that once there he relaxed and enjoyed talking to "everybody that he can talk to." Her son encouraged her to go, and was freer when she was gone. She also received encouragement from other family members to continue attending the Program.

Ms. $P$ described the contributions that students in the Skills Plus Program made to each other in terms of the efforts she made "to be up, 
instead of down." She said that she enjoyed meeting "those people," and tried to greet everyone, "even if they can't answer when I say 'Hello."' She considered the social aspect of the Program to be significant. In terms of general community involvement, Ms. P told about a trip to her local senior citizens group. "They had jewels dripping from their fingers, and I felt like a wasp, no, a waif." She believed that the Skills Plus Program benefitted the community because it got people out of their home. "I feel that it's a good thing for old people to be able to get out and go and meet somebody else, and a lot of 'em in the same situation you're in. Otherwise they'd stay in their room and you find them dead.... And this [the Skills Plus Program] gives you a sense of life, that's what it is...now-a-days, everybody lives old."

Ms. $\mathrm{P}$ believed it was important to have the classes taught by certified therapists, because "they know the things that help." She perceived improvement in the conditions of all the students in the Program, and said that seeing other people's improvement helped her to improve her skills and her attitude.

The only drawback to the Program Ms. P could think of was that "you have to go there and you don't feel like it."

Ms. $\mathbf{M}$

Ms. $\mathrm{M}$ is a 74-year-old woman who, at the time of the interview, was living in a private house with her husband and a tenant. She had adult children and grandchildren who lived in the local area and visited regularly. 
She fed and toileted herself independently. Her husband was her main caregiver, and he assisted her with bathing and dressing, and also did the cooking and light housework. Ms. M could walk around the house independently using a walker. She had a wheelchair, and depended upon her husband to take her anywhere.

Ms. M suffered a stroke 3 years prior to the interview. During the 6 months that followed, she received a multiplicity of rehabilitation services in numerous settings. She had been participating in the Skills Plus Program for 2 years and 6 months at the time of the interview.

Ms. M described the environment of the Skills Plus Program as having a very positive tone set by the program specialist. She said that she had not known that organizations still existed that were "that dedicated," and that she was happy there. Always careful to mention exceptions, she expressed admiration for the efforts and struggles of all the students. She added, "We are all very helpful to each other, emotionally, and physically."

Ms. M said participation in the Skills Plus Program had helped her improve her walking and her mobility in her affected arm. However, she had suffered a setback when she fractured her hip, and, at the time of the interview, considered herself "very limited." She said she applied some of the skills she knows, felt stronger bodily, and had "more use of my impeded facilities." She did not believe she had learned any other things at the Program that were useful to her. 
Ms. M credited the Skills Plus Program with meeting some of her needs. Attending the Program regularly offered a "partially structured existence which we wouldn't otherwise have." It gave both Ms. M and her husband an opportunity to get out of the house and be with other people. "We get out of exchanging the same ideas we exchanged 10 years ago." Ms. $M$ considered herself a very strong person, and believed it was important for her to get the physical exercise. She indicated a desire to attend the Skills Plus Program for 4 days a week instead of only two. She believed that spending more hours per week in therapeutic activity would facilitate improvement of people's conditions, and reduce the length of time they needed to continue attending the Program. However, additional hours that were currently available to attend the Program were difficult for her, and she declined to increase her time there.

Ms. M believed that the Skills Plus Program made a lot of difference for her husband, who accompanied her to the Program. She felt the Program furnished him a release by providing a social connection with the other caregivers, and that their respect for him was good for him. She also believed that the caregiver program bolstered the enthusiasm of the caregivers who participated.

Ms. M believed that she could not make contributions to anyone, although she expressed hope that seeing her effort would encourage other students. She said that students were helping each other. She considered 
herself "further ahead, physically, than many of the others [students]." As for contributions by students to the general community, she thought it would be hard to judge what students did or could do because they did not know each other before they "became handicapped," and because many students were unable to express themselves. However, Ms. M believed that the Program itself was important to the community. "Every penny they spend improving our physical abilities, is money they save supporting and maintaining the completely handicapped people. Because every penny that is spent improving the situation of handicapped people is money well spent...." She thought that most of the students "would not do a thing" without the "opportunity" to participate in the exercises at the Skills Plus Program.

As a drawback to the Program, Ms. M expressed low esteem for one of the teachers. She expressed a wish to see "more things" happen, a wish for better equipment and a better sidewalk, "so people wouldn't be tripping." Ms. E

Ms. $\mathrm{E}$ is an 82-year-old woman who, at the time of the interview, was living in a private home with her husband. She said that her family was available as necessary, but that she did not have to call on them to do things for her. She was independent in daily living activities, and she and her husband did all the housework and shopping. She stated she was "not obstructed in any way as to going anywhere or doing anything." 
Ms. E had her stroke 4 years and 9 months prior to the interview. She had 1 week of therapy while in the hospital, followed by home health and outpatient therapies. Over time she has taken advantage of further opportunities that become available. She had been attending the Skills Plus Program for $41 / 2$ years at the time of the interview.

Ms. $E$ believed that she had learned a tremendous amount from the Skills Plus Program, stating, "I feel that if I had not gone there I would not be in the position I am today." She found the environment of the Program to be an open one, and thought that it was entirely up to each student to benefit from what the Program offered. She said "The challenges are there, if you want to accept them." The main challenge that she felt in the program was "Just to participate to the fullest." At the same time, she mentioned that she saw some students who she believed did not accept that challenge, and attend the Program "just for the company, just to be with people."

Ms. E said that the Skills Plus Program met her needs by keeping her on her toes. She said that even though she did a lot of work at home, she was "forced" to perform physical activity on a regular basis by participating in the Program. She specifically mentioned that she continued daily to find more ways to use her affected arm, and that she had improved mobility. She had learned what she had to do to improve her condition, and she said she felt more self-sufficient as a result of attending the Program. She did not find a 
need to go to the Program for social reasons, nor that it affected her relationships with other people.

Ms. E believed that her husband benefitted from the caregivers program, and that her family feels she has benefitted. She did not think about attending the program more often, because she had many other things going on in her life.

Ms. $E$ believed that certified therapists would have "access to all the newer and better ways." However, she added that she had not tried a physical education person, so that she could not determine who would be a better teacher for the classes.

Ms. E believed that the students contributed to each other's benefit by trying to help and encourage each other. She considered that an important aspect of the Program, and believed it would carry over to the community. She believed that the community benefitted from the Skills Plus Program because some of the students would otherwise be "out in the cold" and do nothing. "The benefits [that the students get] I think are worth more than anything anyone could contribute."

Many of Ms. E's comments about the Program were in terms of other students. A drawback Ms. E reported in the Skills Plus Program is that it "irked" her to see people who, in her estimation, were not applying themselves, not trying hard enough, and who came to the Program for social reasons only. She also believed that some of the people needed to be 
challenged more in class to participate, and encouraged more to use their affected limbs.

\section{Results}

The data obtained from the interviews with the eight informants were analyzed to determine common themes and to answer the research questions. All of the themes that emerged from the interview data were organized into categories as a preparatory step to answering the research questions. In this section, answers to the first two research questions are presented in terms of these themes and categories. The accuracy of the Skills Plus Mission Statement is examined in answering research question three.

\section{Benefits and Drawbacks}

Question 1. What are the benefits and drawbacks perceived by the students in the Skills Plus Program? 


\section{Benefits}

Benefits perceived by the informants fell into the categories of exercise, transfer of learning to home and daily activities/improvements in condition, independence and self-sufficiency, group activity, social support, enjoyment, and working toward goals. All but the last category were mentioned by six or more of the eight participants interviewed.

Exercise. All of the participants who were interviewed reported that exercise was an important aspect of their participation in the Skills Plus Program. They stated that they exercised more and better in the group at the Program than they would have at home. While each one affirmed the importance of regular exercise, three of the informants stated that they would not exercise on their own. Two others had noted a decline in their physical strength and abilities when they had not attended the Program for as little as one month. even though they both claimed to exercise at home.

\section{Transfer of Learning to Home and Daily Activities/} Improvements in Condition. All of the participants identified ways that things learned and practiced at the Skills Plus Program transferred to their daily lives at home. There were several improvements in their general condition and abilities that they attributed to their participation in the Skills Plus Program. Six informants specifically mentioned improvements in 
walking or general mobility, and five mentioned improved use of their affected arm or hand. Four participants described techniques or equipment that they had learned and used in the Program that they subsequently used or wanted to use at home. Other benefits identified were improved facial control to prevent drooling, staying limber, increased strength which facilitated bathing activities, and encouragement to find ways to perform tasks that at first appear too difficult.

Independence and Self-Sufficiency. Six of the eight informants believed that their participation in the Skills Plus Program boosted their feelings of self-sufficiency. Two participants stated that the Program helped them learn skills that they need to help themselves. Three said they felt encouraged to find ways of doing things at home, and described specific ways they have managed to independently perform various activities that were important to them.

Group Activity. Six of the eight participants considered the group interaction and support they experienced at the Skills Plus Program to be both valuable and beneficial aspects of their participation. They spoke variously about the benefits of being with other people rather than alone, of working with other people as a team, of the intellectual challenge provided by communication with other people, of enjoying the social contact and 
companionship, and of the opportunity to encourage other people. Four informants said that they learned a lot or were motivated by their association with other students, especially those who were "worse off" than themselves. One other informant stated that while she was not interested in socializing with other participants, she believed that the social connection that her husband found with other caregivers afforded him a release.

Social Support. When asked to describe the environment of the Skills Plus Program, six of the eight informants responded with thoughts about the group and about their relations with the other participants. In addition to the benefits of group activity discussed above, four of the informants specifically mentioned the importance of the social support they received from being with people at the Skills Plus Program. Five informants looked forward to the opportunity to be out of the house, to meet other people, and to keep busy. Two people appreciated both the variety added to their week and the effect of a regular schedule. One specifically appreciated the opportunity for positive feedback.

Enjoyment. Six of the informants regarded their enjoyment of their participation in the Skills Plus Program to be a significant factor from which they obtained benefit. They described it variously as an opportunity to enjoy life, to talk to people, to laugh, to enjoy companionship, to feel better, and to 
lift depression. Four informants specifically indicated the improvements in their mental attitude about themselves and their situation. They spoke of feeling uplifted, less of a prisoner, mentally stimulated, less negative, and just feeling better.

Working Toward Goals. One informant appreciated the benefit of setting personal goals in the classes and working toward them.

\section{Drawbacks}

Drawbacks were perceived by seven of the eight informants; one of the informants stated that the experience had all been positive. Drawbacks that emerged from the interviews fell into the categories of transportation, other participants, lack of challenge. lack of equipment, lack of individual attention, and other. Each category was mentioned by four or fewer of the eight participants interviewed.

Transportation. Transportation to the Skills Plus Program is the responsibility of each individual. Four of the eight informants mentioned the difficulty involved in getting to the Program as a drawback. Of these four, two, who are brought by caregivers, mentioned inconvenience; one addressed the difficulty for her husband in helping her prepare and driving her there; 
and one, who uses outreach services with her caregiver, complained of the discomfort of feeling like a rag doll on the bus.

Other Participants. Four informants were critical of the behavior or performance of other students, and regarded this as a drawback to the Program. Three of these informants were disturbed when other students did not appear to apply themselves or to respond to the efforts of the teachers and other students to help them. Two of the informants did not believe that people should come to the Skills Plus Program just to socialize, without focusing on improving their skills. One of the informants reported being disturbed by the discussions amongst the caregivers. In contrast, one other informant suggested there be more time for social activity.

Lack of Challenge. Three informants stated that they wished the Skills Plus Program was more challenging. One of the three informants suggested the use of more or different activities to keep people moving all the time, and one believed that the participants needed to be encouraged and challenged more to participate in activities. Two of the three informants specifically mentioned the Independent Living Skills classes as needing to be more challenging. 
Lack of Equipment. Two informants believed that the Program needed more or better equipment, and wanted to see an increased number of activities offered. They each believed that the Program was doing well, but could do better. They also each recognized that financial limitations were a factor in determining the extent of activity possible.

Lack of Individual Attention. Two informants regarded the need for more individual activity and assistance as a drawback to the Skills Plus Program. The first believed that smaller class size would make classes more beneficial for individual students. The second described group experience as most beneficial for people who are average in the group. She believed that people who were at the extremes, and who needed a particular kind of help, might not get the assistance they need. She specifically mentioned students who had been attending the Program for a few years and who continued to have communication difficulties.

Other Drawbacks. One informant said that some of the classes, especially exercise classes, were too repetitive and unchanging. He complained that the repetition bored him. One informant expressed low esteem for one of the instructors. One complained about the poor condition of the sidewalks at the facility. 


\section{Quality of Life}

Question 2. In what ways, if any, does participation in the Skills Plus Program contribute to improved quality of life for students and their caregivers?

The definition of quality of life used for this study is a person's subjective perception of life satisfaction and functional ability. All of the informants believed that participation in the Skills Plus Program improved their quality of life in some way. Responses fell into several categories, some of which are similar to the categories for Question One, and most of which involved improved quality of life for the participants themselves. These categories of improved quality of life are attitude and depression; selfimprovement and learning; social interaction; and activity, life structure. and occupation. Improvements in quality of life for family and caregivers are grouped here in to one category.

Attitude and Depression. All eight of the participants interviewed described effects of participation in the Skills Plus Program upon their attitudes about themselves and their lives. Two informants specifically mentioned improvements in attitude per se. Six informants recognized the active role they and other participants took in helping each other during 
Program activities, both emotionally and physically; and two of them described their appreciation of having been helped as well as their efforts to help other participants maintain a positive attitude and enjoy themselves. One informant described an increased sense of confidence in performing activities in the community on which he had worked at the Skills Plus Program. Three informants described the ease with which they could slide into depression, and credited their participation in the Program with helping them to accept their situation. Four informants reported appreciating the opportunities to laugh with others and to sometimes laugh about themselves. Two informants credited the Skills Plus Program with giving them a sense of being alive.

Self-Improvement and Learning. All eight informants described ways in which they had improved their functional abilities while attending the Skills Plus Program. Improved mobility for increased independence was mentioned by five informants. Improved use of the affected hand and learning one-handed techniques for increased independence and reduced reliance on other people was mentioned by five informants. Two of the participants specifically mentioned that they each felt like less of a burden on their families. Other skills learned were described variously as control of the mouth and drooling, cooking techniques for independence in the kitchen, ability to communicate with people who may not understand you, 
maintaining strength to keep from declining physically, and mental stimulation. One informant stated that his patience and tolerance for other people had risen greatly as a result of his attendance at the Program. Two informants expressed surprise at having learned from and been encouraged by participants whom they considered to be in worse condition than themselves.

Social Interaction. For all the informants, the group nature of the Skills Plus Program was an important factor of the Program. Seven of the eight informants perceived ways that the group nature of the Program improved their own sense of life satisfaction. These ways were described variously as making life better, teamwork, enjoyment. working as a group toward a goal, making contact with other people, making new friends, discovering new worlds, having a sense of improving one's condition, feeling better, and not being alone. However, one informant stated specifically that she did not attend the Skills Plus Program for socialization.

Activity, Life Structure, and Occupation. Attending the Skills Plus Program was described as an important part of their weekly activity by six of the eight participants interviewed. For each of them, going to the Program was an opportunity to get out of the house, to be actively occupied, and to interact with other people. Four informants stated that they would 
probably not otherwise have a place to go or a way of meeting people. Two informants mentioned that they appreciated the partial structure furnished to their life by attendance at the Program.

Family and Caregivers. Seven informants perceived ways that their participation in the Skills Plus Program improved quality of life for their family and caregivers, while the eighth informant reported that he had distant relationships with his family and did not believe they were affected by his activities. Five informants reported that members of their families believed that the informants were benefitting from the Program, encouraged them to attend, and were happy that they are participating. Two informants stated that their attendance at the Program reduced the strain on their caregivers because it gave the informants something to do, and because it got them out of the house, it gave the caregiver some respite time. The monthly caregiver meetings held at the Skills Plus Program were mentioned by three informants as a great benefit to their main caregivers. Two informants whose family members accompanied them to the Program believed that the caregivers benefitted from the socializing and conversations with each other, which provided an outlet and release for the caregivers. 


\section{Skills Plus Mission Statement}

Question 3. In what ways does the Mission Statement created by the Skills Plus administration and staff accurately describe the benefits perceived by the students?

The Skills Plus Mission Statement consists of three parts, and is as follows.

Skills Plus is committed to enriching the lives of the people we serve by:

---providing a safe, supportive learning environment that stimulates and challenges

---offering opportunities for increased independence, enhanced self-worth, and improved socialization skills

--encouraging students to achieve their maximum potential in making positive contributions to each other and to the community.

Each part is discussed individually.

Part 1. Providing a safe, supportive learning environment that stimulates and challenges. All of the participants interviewed perceived the environment at the Skills Plus Program to be safe, supportive. and 
stimulating, and five of the informants found the Program challenging. They variously described the environment as a positive one where they felt encouraged and motivated to learn.

Three of the informants expressed a wish for more challenge in all or parts of the Program, and two suggested a need for more equipment.

Part 2. Offering opportunities for increased independence, enhanced self-worth, and improved socialization skills. All of the participants interviewed described ways in which they became more independent or self-sufficient as a result of activities they had learned and practiced at the Skills Plus Program. All of the participants interviewed also felt enhanced self-worth and self-esteem, usually ensuing from their strengthened sense of self-sufficiency and reduced feeling of dependence on other people.

Seven of the eight participants interviewed considered the social aspect of the Skills Plus Program to be significant and beneficial, although five of them stated that they did not believe they had problems with socialization prior to attending the Program. Two of the informants described ways in which their own socialization skills per se had improved. 
Part 3. Encouraging students to achieve their maximum potential in making positive contributions to each other and to the community. Positive contributions to each other was seen by the participants interviewed in the form of the help and encouragement the students gave each other while attending the Skills Plus Program. All eight of the informants indicated that this mutual help and encouragement was a key element of the Program, and of great benefit. Three of the informants described their own efforts to encourage other people to do their best.

Contributions to the general community was a problematic subject. At the time of the interviews, none of the informants felt capable of making personal contributions to the community. Three informants expressed a desire to do so and a hope that it would be possible in the future. Two informants believed that contributions the students made to each other would carry over to benefit the community.

Seven of the eight participants interviewed considered the existence of the Skills Plus Program itself to be a positive benefit not only to themselves but to the general community as well.

Summary. The participants interviewed generally considered the Skills Plus Mission Statement to be an accurate description of the benefits they perceived while attending the Program. 


\section{CHAPTER 5 \\ DISCUSSION, IMPLICATIONS, RECOMMENDATIONS, AND SUMMARY}

\section{Discussion}

The Skills Plus Adult Education Program, like the Cabrillo College Stroke Center, was started by citizens in the community who recognized the need for long-term rehabilitation, education, and training for people who suffered from the effects of stroke and other neurological disorders. The results of the current study indicate that the Skills Plus Adult Education Program provides for long-term needs of survivors of stroke by providing continuing therapeutic activities in a classroom environment, achieving the aims of its mission.

Studies in the literature have documented that the interpersonal processes inherent in group approaches to therapy promote wellness (Duncombe \& Howe, 1995; Gauthier, et al., 1967; Kurasik, 1967; Neistadt \& Marques, 1984; Versluys, 1980). Results of the current study further demonstrate the benefits of peer support and encouragement to class members. Participants in the Program who were interviewed for this study reported an increased sense of self-sufficiency and independence, as well as enhanced self-worth and self-esteem. 
Implications for Occupational Therapy Practice and Education

Serving individuals who are experiencing problems in daily living resulting from the aging process or medical problems has been delineated as a role and function of occupational therapy in long-term care programs (American Occupational Therapy Association, 1989b). The examples of settings mentioned were "skilled and intermediate care facilities, adult day care centers, half-way houses, congregate living facilities, and private residences" (p. VI.39). Adult education classes in the schools can be added to this list of arenas in which to provide needed occupational therapy services to people with severe disabilities.

Hasselkus and Kiernat (1989) stated that by the year 2020, people of age 65 and older will outnumber teenagers by 2 to 1 in the United States. They issued a challenge for occupational therapy to become proactive in the realm of geriatric health care concerns. The context of occupational behavior and health of aging individuals is a unique area for practice in which occupational therapy has a great deal to offer, and they challenged occupational therapists to "nurture nontraditional models of occupational therapy that address service and reimbursement needs" (p. 79). As length of hospital stay shortens. and reimbursement for medical care becomes increasingly limited, there is increasing pressure for posthospitalization programs in the community, creating opportunities for occupational 
therapists to develop and refine their roles in community-based programs. Programs such as Skills Plus provide an opportunity for occupational therapists to create a supportive environment in which to maintain and continue therapeutic activities in areas of physical, cognitive, and social function that began during medical treatment. It has been predicted that the 21 st century will bring an increased population of persons with impairments and chronic conditions, whose independence and quality of life may be threatened by chronic disability as well as by immobility and restricted environmental stimulation (American Occupational Therapy Association, 1989b; Yerxa, 1994). Yerxa (1996) advocated changes in the health care system "so that a model of long-term commitment to improving life opportunities for people with disabilities takes the place of the current paradigm of acute medical care" (p. 265). She cited several examples taken from the literature of new models of occupational therapy practice in various community settings, and urged therapists to continue developing more models of community-based practice as a needed alternative to high-cost, hospital-based practice. Results of the current study indicate that the classroom can provide a context in which individuals can work on skills in performance areas and performance components, toward maximum functional abilities and improved quality of life.

Review of the drawbacks to the Skills Plus Program perceived by participants in the current study, together with the implications for 
occupational therapy discussed in the preceding section, reveals implications for occupational therapy education as well. Most occupational therapy education emphasizes acute medical and acute rehabilitation settings, and education in group work is often limited to courses that teach psychiatric occupational therapy practice. Additional education and training could be offered on work with groups in the area of occupational therapy for physical disabilities. Course work on working with elders, the psychology of recovery and adjustment to acquired disabilities. and long-term treatment planning as individuals progress through different stages of recovery could also be added to the occupational therapy educational curriculum.

\section{Recommendations for Further Research}

There have been studies in the literature regarding the effect of chronic illness and stroke on members of the family and other caregivers. An in-depth study could be conducted to assess the particular needs of families of the students of the Skills Plus Program, in order to improve the Program and better serve the community.

The current study was limited to students who have attended the Skills Plus program for at least 6 months. There are occasionally students who leave at the end of one 8-week session. A study could be conducted to determine the reasons why people discontinue, to find the needs that are not 
being met by the existing Program, and/or to propose other community programs to meet those needs.

Drawbacks to the Program perceived by the participants in the study included lack of challenge, lack of equipment, lack of individual attention, and boredom. These aspects of the Program could be studied further, in order to better serve the individual needs of each participant. In addition, a study could be conducted to determine whether particular drawbacks are noted more by individuals in particular stages of post-stroke recovery. This information could be used to better serve the needs of each individual.

The current study emphasized the needs of elders in the community. Further research could examine the needs of survivors of stroke who belong to younger age cohorts.

\section{Summary}

The disruption in life course and occupational roles caused by the residual impairments in the aftermath of stroke are not fully addressed under traditional, medically oriented practice. To provide needed long-term rehabilitation and education for individuals recovering from stroke, occupational therapists are developing and refining their roles in communitybased programs. 
Skills Plus is an Adult Education Program that provides rehabilitation and training for people who live with impairments resultant from strokes. It was created by therapists as a response to a perceived need in the community, and operates within the scope of an educational model. In the classroom context occupational therapists create a supportive environment in which individuals can maintain and continue therapeutic activities in areas of physical, cognitive, and social function that began during medical treatment.

In-depth interviews were utilized to assess participants' reactions to the Skills Plus Program relative to its mission. Participants interviewed generally considered the Skills Plus Mission Statement to be an accurate description of the benefits they perceived while attending the Program. Increased independence and self-worth were reported. The Program is both valuable and cost-effective for the community and can serve as a model for similar programs in the State of California and across the nation. 


\section{REFERENCES}

American Occupational Therapy Association (1994). Uniform terminology for occupational therapy - Third edition. American Journal of Occupational Therapy, 48, 1047-1054.

American Occupational Therapy Association. (1989a). Occupational therapy's role in independent or alternative living situations. In Reference Manual of the Official Documents of the American Occupational Therapy Association,Inc. (pp. VI.35 - VI.37). Rockville. $\mathrm{MD}$ : Author.

American Occupational Therapy Association. (1989b). Roles and functions of occupational therapy in long-term care: Occupational Therapy and activity programs. In Reference Manual of the Official Documents of the American Occupational Therapy Association,Inc. (pp. VI.39 VI.41). Rockville, MD: Author.

Becker, G. (1993). Continuity after a stroke: Implications of life-course disruption in old age. The Gerontologist, 33, 148-158.

Christiansen, C. (1991). Occupational therapy: Intervention for life performance. In C. Christiansen \& C. Baum (Eds.), Occupational therapy: Overcoming human performance deficits pp. 2-43). Thorofare, N.J.: Slack. 
Clark. P. G. (1995). Quality of life, values and teamwork in geriatric care: Do we communicate what we mean? Gerontologist, 35, 402-411.

Cole, J. A. (1979). What's new about independent living? Archives of Physical Medicine and Rehabilitation, 60, 458-461.

Crewe, N. M. (1979). Independent living: An idea whose time has come (Editorial). Archives of Physical Medicine and Rehabilitation, 60, 433-434.

Davidson, H. (1991). Performance and the social environment. In

C. Christiansen \& C. Baum (Eds.), Occupational Therapy (pp.143-177). Thorofare, NJ: Slack.

DeJong, G., \& Hughes, J. (1982). Independent living: Methodology for measuring long-term outcomes. Archives of Physical Medicine and Rehabilitation, 63, 68-73.

DePoy, E. \& Gitlin, L. N. (1994). Introduction to research: Multiple strategies for health and human services. St. Louis, Mosby.

Duncombe, L. W., and Howe, M. C. (1995). Group treatment: Goals, tasks, and economic implications. The American Journal of Occupational Therapy, 49, 199-205.

Farquhar, M. (1995). Elderly people's definitions of quality of life. Social Science and Medicine, 41, 1439-1446. 
Gauthier, L., Dalziel, S. \& Gauthier, S. (1987). The benefits of group occupational therapy for patients with parkinson's disease. The American Journal of Occupational Therapy, 41, 360-365.

Green, B. C., Pratt, C. C., \& Grigsby, T. E. (1984). Self-concept among persons with long-term spinal cord injury. Archives of Physical Medicine and Rehabilitation, 65, 751-754.

Hasselkus, B. R., and Kiernat, J. M. (1989). Nationally speaking - not by age alone: Gerontology as a specialty in occupational therapy. The American Journal of Occupational Therapy, 43, 77-79.

Kelly-Hayes, M. \& Paige, C. (1995). Assessment and psychologic factors in stroke rehabilitation. Neurology, 45 (Suppl 1), S29-S32.

Kurasik, S. (1967). Group dynamics in the rehabilitation of hemiplegic patients. Journal of the American Geriatrics Society, 15, 852-855.

McColl, M. A., \& Friedland, J. (1994). Social support, aging, and disability. Topics in Geriatric Rehabilitation, 9, 54-71.

Neistadt, M., \& Marques, K. (1984). An independent living skills training program. American Journal of Occupational Therapy, 38, 671-676.

Pedretti, L. W. (1996). Occupational performance: A model for practice in physical dysfunction. In L. W. Pedretti (Ed.), Occupational therapy: Practice skills for physical dysfunction, 4th edition (pp. 3-12).

St. Louis: C. V. Mosby. 
Pedretti, L. W. \& Pasquinelli, S. (1990). A frame of reference for occupational therapy in physical dysfunction. In L. W. Pedretti \& B. Zoltan (Eds.), Occupational therapy: Practice skills for physical dysfunction, 3rd edition (pp. 1-17). St. Louis: C. V. Mosby.

Pendleton, H. M. (1990). Occupational therapists' current use of independent living skills training for adult inpatients who are physically disabled. In J. A. Johnson \& E. Yerxa (Eds.), Occupational science: The foundation for new models of practice (pp. 93-108). New York: Haworth Press.

Perry, D. (1995). Researching the aging well process. American Behavioral Scientist, 39, 152-171.

Reilly, M. (1969). The educational process. American Journal of Occupational Therapy, 23, 299-307.

Safran, D. G., Graham, J. D., Osberg, J. S. (1994). Social supports as a determinant of community-based care utilization among rehabilitation patients. Health Services Research, 28, 729-750.

Skills Plus (1996). Skills Plus: A program to help physically challenged adults improve social, physical, and cognitive skills [Brochure]. Santa Clara, CA: Skills Plus. 
Versluys, H.P. (1980). The remediation of role disorders through focused group work. The American Journal of Occupational Therapy, 34, 609-614.

Yerxa, Elizabeth J. (1994). Dreams, dilemmas, and decisions for occupational therapy practice in a new millennium: An American perspective. American Journal of Occupational Therapy, 48, 586-589.

Yerxa, Elizabeth J. (1996). The social and psychological experience of having a disability: Implications for occupational therapists. In L. W. Pedretti (Ed.), Occupational therapy: Practice skills for physical dysfunction, 4th edition (pp. 253-274). St. Louis: C. V. Mosby.

Yerxa, E. J., Clark, F., Jackson, J., Pierce, D., Zemke, R. (1990). An introduction to occupational science: A foundation for occupational therapy in the 21 st century. In J. A. Johnson \& E. Yerxa (Eds.), Occupational science: The foundation for new models of practice (pp. 1-17). New York: Haworth Press. 
APPENDIX A

SKILLS PLUS MISSION STATEMENT 


\section{SKILLS PLUS MISSION STATEMENT}

Skills Plus is committed to enriching the lives of the people we serve by

Providing a safe, supportive learning environment that stimulates and challenges

Offering opportunities for increased independence, enhanced self-worth, and improved socialization skills

Encouraging students to achieve their maximum potential in making positive contributions to each other and to the community 
APPENDIX B

PERMISSION LETTER 


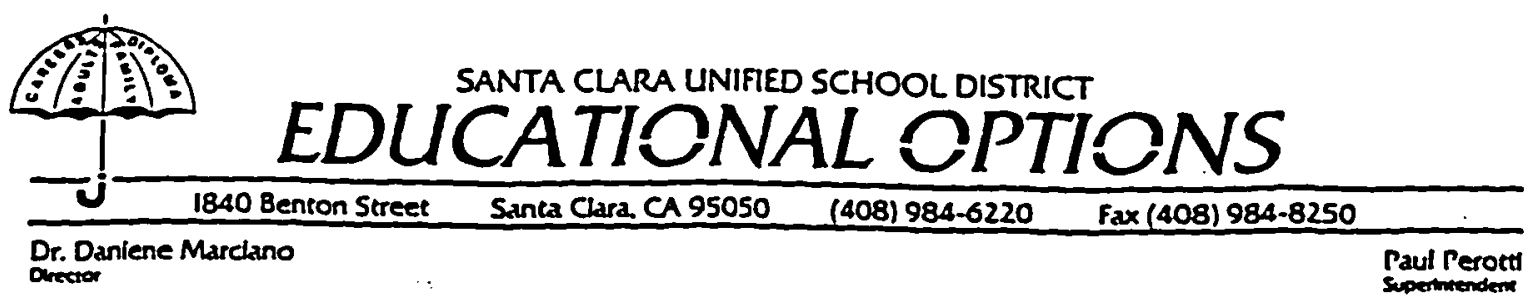

May 1, 1996

Permission is given to Sharon R. Altus OTR, Adult Education Instructor, to conduct in depth interviews with students at the Skills Plus Program. These interviews are for use in her master's thesis in completion of her M.S. degree in occupational therapy. It is understood that all information that might identify individual students will be kept confidential.

Sincerely,

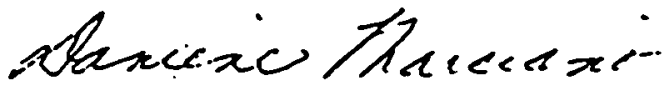

Dr. Daniene Marciano

Director

Educational Options 


\section{APPENDIX C}

PARTICIPANT CONSENT FORM 


\section{Agreement to Participate in Research}

Responsible Investigator: Sharon R. Altus, OTR Daily Living skilis Instructor Masters. Candidate in Occupational Therapy

Title of Protocol: The Relationship of the Skilis Plus Adult Education Program to its Mission

I have been invited to participate in a research study of students experiences at and reactions to the skilis plus Program. The aim of the study is to determine what benefits people may receive and whether the education model works for extended long-term therapeutic activity. Results of this study should enhance the skilis Plus Program and may possibly be used to support establishment of similar programs in other school districts.

I understand that I will be participating in in-depth interviews, following an interview guideline prepared by the researcher. I am willing to communicate honestly and candidly about my experiences that relate to skilis Plus. I understand that the conversation will be audiotape recorded and later transcribed. I realize that at times my memories may be distressing to me, and that the interviewer will not press me to speak of personal events that I do not wish to reveal. I understand that I will remain anonymous, that any identifying information will not be used in this study and that all possible measures will be taken to insure confidentiality. 
I will meet the researcher either at skills plus or at another location that is convenient to me at a time that is convenient to me and to the researcher. The entire interview should take from $1-3$ hours. I understand that I will receive no payment for my participation, and also that there will be no cost to me. The benefits I may receive from this study are the possible improvement of the skilis plus program, and knowing that I have helped in sharing information about this program with the larger community.

I am aware that I have the right to decline to participate in this study. If I do participate. I have the right to withdraw from this study at any time. such decisions will not prejudice my relations with the researcher, the skilis plus Program nor with san Jose state university.

I understand that this study will be presented to the Department of Occupational Therapy at san Jose state University, and may be published in a national professional

journal. I understand that there will be no identifying information of the participants included in any presentation or publication.

I may address any questions regarding this research to sharon Altus, OTR (researcher) at (415)493-7420. or (408)3717497. Any complaints I may have about the research may be addressed to Kathleen Schwartz, Ed.D, OTR, Acting Chair, Department of Occupational Therapy, at (408) 924-3075. Questions or complaints about research, subject's rights, or research-related injury may be presented to serena stanford, Ph.D.. Associate Academic Vice President for Graduate studies and Research, at (408)9242480 .

Part. Init. Res. Init. 
I give my voluntary consent to participate in this study. I have read and understand the above information.

Participant's signature

$$
\text { Date }
$$

I agre:e to include the person whose signature appears above in my research. This person has been fully informed of his or her rights. 
APPENDIX D

INTERVIEW GUIDELINES 


\section{Demographics}

Age:

Lives With:

Family Support:

Assistance Needed in Basic ADL's: (bathing; dressing; toileting; eating)

Housework, Cooking:

Mobility: (in the home; outside)

Driving:

Date of Stroke:

Therapy Following Stroke:

Time at Skills Plus:

Other Activities, Getting Out of Home:

Date of Interview / Length:

\section{Guidelines for Interview Questions}

1. Tell me about your experiences at Skills Plus?

2. Tell me about the environment of the program?

3. Tell me about your experience after you left/leave Skills Plus?

Describe for me how skills learned here help you out in the real world?

4. In what ways did/does the program meet your needs?

5. What about the program makes you stay? / What made you decide to leave? What is important to you about the program or about coming to the program?

6. Do you feel more self-sufficient? Has participation in the program helped you to stay at home rather than going into a long-term facility?

7. What effect does this program have on your family, caregivers? what difference does it make to them?

8. How does coming to the program affect your relationships with other people -- socialization?

9. In what ways do you and other students here make positive contributions to each other and the community? 


\section{APPENDIX E}

\section{GUIDELINES ADDED DURING INTERVIEW PROCESS}




\section{Guidelines Added During the Interview Process}

10. What importance do you see in having the classes taught by Certified Therapists, who are medical professionals?

11. Have you thought at all about going 4 days a week?

12. Why should the community be supporting Skills Plus? Why should the State, why should our tax money be going to Skills Plus? What benefit is there to the community that Skills Plus exists?

Other facilities or programs:

Private therapy:

Costs: 
APPENDLX F

INTERVIEW DATA FORM 


\section{INTERVIEW DATA FORM}

\section{Demographics}

Age:

Lives With:

Family Support:

Assistance Needed in Basic ADL's: (bathing; dressing; toileting; eating)

Housework, Cooking:

Mobility: (in the home; outside)

Driving:

Date of Stroke:

Therapy Following Stroke:

Time at Skills Plus:

Other Activities, Getting Out of Home:

Date of Interview / Length:

\section{Guidelines for Interview Questions}

1. Tell me about your experiences at Skills Plus?

2. Tell me about the environment of the program?

3. Tell me about your experience after you left/eave Skills Plus?

Describe for me how skills learned here help you out in the real world?

4. In what ways did/does the program meet your needs? 
5. What about the program makes you stay? / What made you decide to leave? What is important to you about the program or about coming to the program?

6. Do you feel more self-sufficient? Has participation in the program helped you to stay at home rather than going into a long-term facility?

7. What effect does this program have on your family, caregivers? what difference does it make to them?

8. How does coming to the program affect your relationships with other people -- socialization?

9. In what ways do you and other students here make positive contributions to each other and the community?

\section{Guidelines Added During the Interview Process}

10. What importance do you see in having the classes taught by Certified Therapists, who are medical professionals?

11. Have you thought at all about going 4 days a week?

12. Why should the community be supporting Skills Plus? Why should the State, why should our tax money be going to Skills Plus? What benefit is there to the community that Skills Plus exists? 


\title{
Research Questions
}

This study will explore the following questions:

1. What are the benefits and drawbacks perceived by the students in the Skills Plus Program?

2. In what ways, if any, does participation in the Skills Plus Program contribute to improved quality of life for students and their caregivers?

3. In what ways does the Mission Statement created by the Skills Plus administration and staff accurately describe the benefits perceived by the students?

\section{SKILLS PLUS MISSION STATEMENT}

SKILLS PLUS IS COMMITTED TO ENRICHING THE LIVES OF THE PEOPLE WE SERVE BY

\author{
PROVIDING A SAFE, SUPPORTIVE LEARNING \\ ENVIRONMENT THAT STIMULATES AND CHALLENGES \\ OFFERING OPPORTUNITIES FOR INCREASED \\ INDEPENDENCE, ENHANCED SELF-WORTH, AND \\ IMPROVED SOCLALIZATION SKILLS \\ ENCOURAGING STUDENTS TO ACHIEVE THEIR \\ MAXIMUM POTENTIAL IN MAKING POSITTVE \\ CONTRIBUTIONS TO EACH OTHER AND TO THE \\ COMMUNITY
}

Other facilities or programs:

Private therapy:

Costs: 